\title{
Platanus orientalis Leaf Mediated Rapid Synthesis of Catalytic Gold and Silver Nanoparticles
}

Shriya Shende ${ }^{1}$, Komal A Joshi ${ }^{2}$, Anuja S Kulkarni ${ }^{3}$, Chaitanya Charolkar $^{3}$, Vaishali S Shinde ${ }^{3}$, Vijay Singh Parihar ${ }^{4}$, Rohini Kitture $^{5}$, Kaushik $^{2}$ Banerjee $^{6}$, Narayan Kamble ${ }^{6}$, Jayesh Bellare ${ }^{7}$, and Sougata Ghosh ${ }^{8 *}$

${ }^{1}$ Department of Microbiology, Modern College of Arts, Science and Commerce, Ganeshkhind, Pune-411016, India

${ }^{2}$ Institute of Bioinformatics and Biotechnology, Savitribai Phule Pune University, Pune-411007, India

${ }^{3}$ Department of Chemistry, Savitribai Phule Pune University, Pune-411007, India

${ }^{4}$ Department of Biomedical Sciences and Engineering, BioMediTech, Tampere University of Technology, Korkeakoulunkatu 10, 33720, Tampere, Finland

${ }^{5}$ Department of Applied Physics, Defense Institute of Advanced Technology, Girinagar, Pune-411025, India

${ }^{6}$ National Referral Laboratory, ICAR-National Research Centre for Grapes, Manjri Farm, Pune-412307, India

${ }^{7}$ Department of Chemical Engineering, Indian Institute of Technology, Bombay, Powai, Mumbai-400076, India

${ }^{8}$ Department of Microbiology, RK University, Kasturbadham, Rajkot, Gujarat, 360020, India

\begin{abstract}
In an attempt to synthesize novel catalytic gold (AuNPs) and silver nanoparticles (AgNPs) we have used Platanus orientalis leaf extract for both reduction and capping. The synthesis was rapid which completed by $5 \mathrm{~h}$ as indicated by change in colour and development of prominent peak at $540 \mathrm{~nm}$ for AuNPs and $440 \mathrm{~nm}$ for AgNPs, as revealed by UV-visible spectroscopy. The phytogenic nanoparticles showed exotic shapes which included triangles, spheres, hexagons and pentagons as analyzed by high resolution transmission electron microscopy. The optimized processing parameters like salt concentration ( $1 \mathrm{mM}$ concentration of $\mathrm{HAuCl}_{4}$ and $4 \mathrm{mM}$ of $\mathrm{AgNO}_{3}$ ) and the reaction temperature $\left(50^{\circ} \mathrm{C}\right)$ led to faster nanoparticles synthesis. Energy dispersive spectra and X-ray diffraction studies confirmed the elemental gold and silver in AuNPs and AgNPs. Detailed phytochemical characterization using biochemical techniques and gas chromatography mass spectrometry indicated the predominance of ascorbic acid, citric acid, reducing sugars and even starch which may together lead to simultaneous synthesis and capping. Further, AuNPs and AgNPs catalyzed the reduction of 4-nitrophenol (4-NP) to 4-aminophenol (4-AP) using $\mathrm{NaBH}_{4}$ with apparent rate constants of $1.908 \times 10^{-4}$ $\mathrm{min}^{-1}$ and $3.071 \times 10^{-4} \mathrm{~min}^{-1}$, respectively.
\end{abstract}

Keywords: Platanus orientalis; Gold and silver nanoparticles; Phytochemistry; Gas chromatography mass spectrometry

\section{Introduction}

In past two decades, green synthesis of nanoparticles has attracted wide attention owing to their broad spectrum applications in physics, chemistry and medicine. It is important to note that the activity of nanomaterials primarily depend on their size and shape [1]. In spite of availability of diverse physico-chemical methods like microwave assisted, laser ablation, sol-gel, that involve hazardous chemicals, toxic solvents, high temperature and high pressure to fabricate monodispersed nanoparticles, biological routes are preferred and are widely explored in the recent past [2-4]. Hence, there is a continuous need to develop novel eco-friendly, non-hazardous, safe and efficient biological routes for synthesis of stable nanoparticles ideal for well defined physicochemical and therapeutic applications [5,6]. Microbial synthesis are comparatively more labor intensive due to involvement of expensive culture media for inoculums development and maintenance of sterility [7]. Hereby, herbal extracts rich in diverse groups of phytochemicals is preferred for simultaneous synthesis and capping of metal nanoparticles $[8,9]$. Medicinal plants like Dioscorea bulbifera, Dioscorea opposiifolia, Barleria prionitis, Gloriosa superba, Gnidia glauca, Plumbago zeylanica, have exhibited their nanobiotechnological potential towards synthesis of gold, silver, copper, platinum and palladium nanoparticles with biological activities [10-19]. Earlier reports showed that the phytogenic nanoparticles were more biocompatible and bioactive as compared to the chemically synthesized nanoparticles $[13,19]$. Similarly, such nanoparticles might be of utmost commercial importance for physical and chemical applications as well.

In this report, we have synthesized gold and silver nanoparticles using Platanus orientalis. Among diverse medicinal properties of $P$. orientalis, antioxidant, antimicrobial, antiseptic, analgesic, antinociceptive, anti-hepatotoxic, anti-inflammatory and anticancer activities are most significant. It is widely used for treatment of dysentery, knee pain, toothache, opthalmia, blepharitis, conjunctivitis, hemorrhage, dermatological and gastrointestinal diseases, kidney stones, itching, rheumatic and inflammatory diseases [20-24]. However, no reports on synthesis of AuNPs and AgNPs using P. orientalis leaf extract (POLE) are available till date.

This report details on synthesis of AuNPs and AgNPs using POLE with optimized reaction parameters, for the first time. The bioreduced nanoparticles were characterized using UV-visible spectroscopy, high resolution transmission electron microscopy (HRTEM), energy dispersive spectroscopy (EDS), dynamic light scattering (DLS), $\mathrm{X}$-ray diffraction spectroscopy (XRD), fourier transform infrared (FTIR) spectrometry. Both AuNPs and AgNPs Further we evaluated the catalytic potential of the nanoparticles towards reduction of 4-nitrophenol (4-NP) to 4-aminophenol (4-AP) using $\mathrm{NaBH}_{4}$.

\section{Materials and Methods}

\section{Plant extract preparation}

P. orientalis leaves were collected, washed thoroughly and shade

*Corresponding author: Sougata Ghosh, Department of Microbiology, RK University, Rajkot, Gujarat-360020, India; Phone: 919923268332; E-mail: sougata.ghosh@rku.ac.in

Received: February 23, 2018; Accepted: March 28, 2018; Published: April 06 2018

Citation: Shende S, Joshi KA, Kulkarni AS, Charolkar C, Shinde VS, et al. (2018) Platanus orientalis Leaf Mediated Rapid Synthesis of Catalytic Gold and Silver Nanoparticles. J Nanomed Nanotechnol 9: 494. doi: 10.4172/2157-7439.1000494

Copyright: $\odot 2018$ Shende S, et al. This is an open-access article distributed under the terms of the Creative Commons Attribution License, which permits unrestricted use, distribution, and reproduction in any medium, provided the original author and source are credited. 
Citation: Shende S, Joshi KA, Kulkarni AS, Charolkar C, Shinde VS, et al. (2018) Platanus orientalis Leaf Mediated Rapid Synthesis of Catalytic Gold and Silver Nanoparticles. J Nanomed Nanotechnol 9: 494. doi: 10.4172/2157-7439.1000494

Page 2 of 7

dried for 2-3 days to ensure complete removal of moisture. Dried leaves were pulverized to fine powder to increase the surface area. POLE was prepared by suspending $5 \mathrm{~g}$ of leaf powder in $100 \mathrm{~mL}$ of distilled water followed by boiling at $100^{\circ} \mathrm{C}$ for $5 \mathrm{~min}$. Supernatant was collected and filtered through Whatman No.1 filter paper after centrifugation for 10 min at $3000 \mathrm{rpm}$. The filtrate was used for nanoparticles synthesis [17].

\section{Synthesis and characterization of gold and silver nanoparticles}

$5 \mathrm{~mL}$ of POLE was added in $95 \mathrm{~mL}$ of $1 \mathrm{mM} \mathrm{HAuCl}_{4}$ to start AuNPs synthesis which was incubated at $40^{\circ} \mathrm{C}$ for $5 \mathrm{~h}$ under shaking condition. Likewise, $5 \mathrm{~mL}$ of POLE was added into $95 \mathrm{~mL}$ of $1 \mathrm{mM} \mathrm{AgNO}$ solution for synthesis of AgNPs. In order to confirm synthesis, visible colour change was monitored and UV-visible spectra were recorded. Temperature optimization was carried out by varying the reaction temperature from $4^{\circ} \mathrm{C}$ to $50^{\circ} \mathrm{C}$, while respective salt concentrations were varied from 0.3 to $5 \mathrm{mM}$ for concentration optimizatiion. Freshly synthesized nanoparticles were characterized using HRTEM, EDS, DLS and XRD. FTIR was used to characterize the bioreduced nanoparticles as per our earlier reports [10].

\section{Phytochemical analysis}

Biochemical assays were used to evaluate total phenolic content, starch, reducing sugar, ascorbic acid and citric acid in POLE according to our earlier report [10]. Further, GCMS fingerprinting was employed to estimate the predominant phytochemicals in POLE [10,16-19].

\section{Catalytic activity}

Aqueous solution of p-nitrophenol $(2 \mathrm{~mL}, 0.1 \mathrm{mM})$ was mixed with $1 \mathrm{~mL}$ of $\mathrm{NaBH}_{4}(0.1 \mathrm{M})$ solution in quartz cuvettes $(4.5 \mathrm{~mL})$. Addition of $50 \mu \mathrm{L}$ of AuNPs $(10 \mathrm{mM})$ and $20 \mu \mathrm{L}$ of AgNPs $(10 \mathrm{mM})$ separately started the reactions, followed to which immediately time dependent absorption spectra were recorded at an interval of 5 min intervals for 30 min at room temperature using UV-vis spectrophotometer. Deionized water was used as reference for background subtraction [14,16,17].

\section{Results}

\section{UV-visible spectroscopy and optimization studies}

Bioreduction of $\mathrm{Au}^{3+}$ ions were initiated on addition of POLE in $\mathrm{HAuCl}_{4}$ solution that was confirmed by change of pale yellow colour to ruby red. Similarly conversion of $\mathrm{Ag}^{+}$to $\mathrm{Ag}^{0}$ was confirmed when brown colour developed on mixing POLE with $\mathrm{AgNO}_{3}$ solution. UVvisible spectroscopy showed signature peaks which confirmed the formation of AuNPs and AgNPs. Synthesis of AuNPs was very rapid which showed a sharp increase in the peak at $540 \mathrm{~nm}$ at $1 \mathrm{~h}$ which increased till $3 \mathrm{~h}$ (Figure 1A). However, further incubation till $5 \mathrm{~h}$ showed no increment in the peak suggesting that complete reduction was achieved within $3 \mathrm{~h}$. In case of AgNPs, although no significant peak was found till 30 mins, from 1 hour a sharp peak was spotted at $440 \mathrm{~nm}$ that was found to increase till $4 \mathrm{~h}$ (Figure 1B).

Temperature optimization studies revealed that the rate of synthesis increase with the increase in temperature (Figure 2A and 2B). The lowest rate of synthesis of AuNPs was found at $4^{\circ} \mathrm{C}$ while the highest was found at $50^{\circ} \mathrm{C}$. Similarly, for AgNPs as well the same trend was observed. Concentration optimization studies indicated that the salt concentration plays a vital role in the rate of synthesis. $1 \mathrm{mM}$ concentration of $\mathrm{HAuCl}_{4}$ was found to be optimum for synthesis of AuNPs while $4 \mathrm{mM} \mathrm{AgNO}_{3}$ gave maximum synthesis of AgNPs (Figure $3 \mathrm{~A}$ and $3 \mathrm{~B}$ ).

\section{HRTEM, EDS, DLS analysis}

HRTEM analysis showed the exotic shapes of the AuNPs synthesized by POLE (Figure 4A-4C). Spherical, triangular and hexagonal nanoparticles dominated the population. Smaller spherical nanoparticles showed a diameter of $44 \mathrm{~nm}$ while the blunt ended hexagonal AuNPs were between 60 to $80 \mathrm{~nm}$ in size. Nanotriangles of equilateral shapes and $80 \mathrm{~nm}$ size were synthesized by POLE. Small spherical and bigger irregular AuNPs were found to adhere to the surface of the triangular nanoparticles. AgNPs synthesized by POLE were found to be very small and mostly spherical which were scattered in discrete groups (Figure $4 \mathrm{D}-4 \mathrm{~F}$ ). The size of the
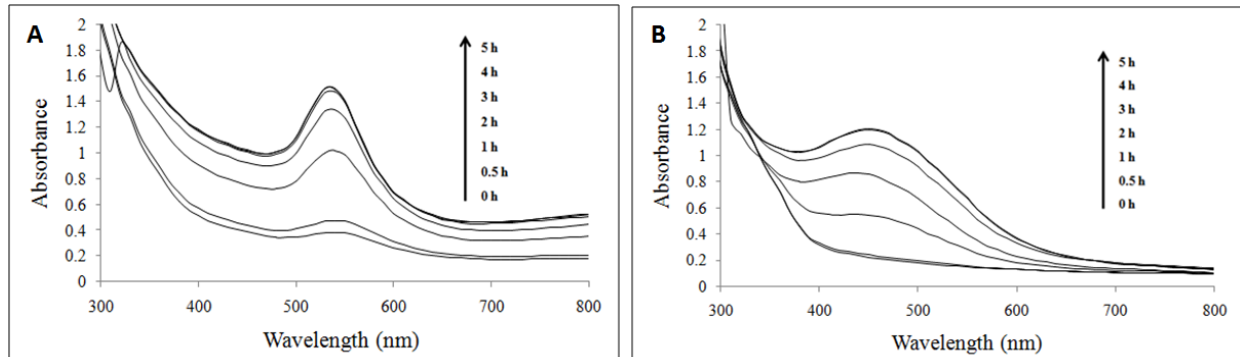

Figure 1: UV-vis spectra recorded as a function of reaction time for nanoparticle synthesis using $\mathrm{POLE}$ at $40^{\circ} \mathrm{C}$ with $(\mathrm{A}) \mathrm{HAuCl}_{4}$ solution and $(\mathrm{B}) 1 \mathrm{mM} \mathrm{AgNO}{ }_{3}$ solution.
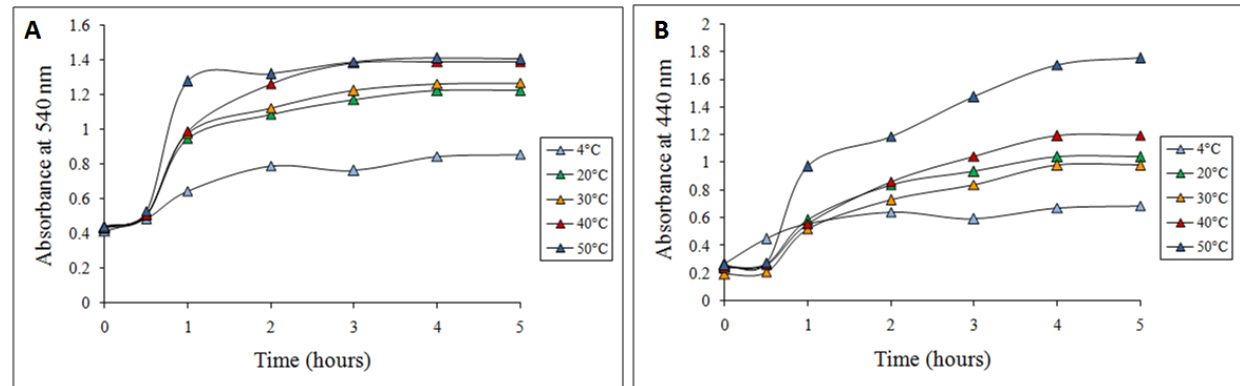

Figure 2: Time course of nanoparticle synthesis using POLE at different reaction temperatures with (A) $1 \mathrm{mM} \mathrm{HAuCl}_{4}$ and $(\mathrm{B}) 1 \mathrm{mM} \mathrm{AgNO}{ }_{3}$. 

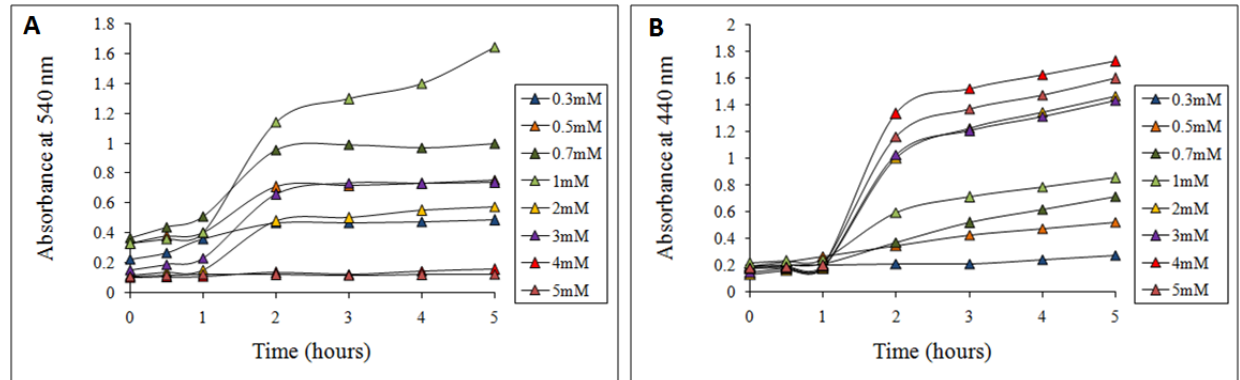

Figure 3: Time course of nanoparticle synthesis using POLE at $40{ }^{\circ} \mathrm{C}$ with $(\mathrm{A})$ different concentrations of $\mathrm{HAuCl}_{4}$ and $(\mathrm{B}) \mathrm{AgNO}_{3}$.
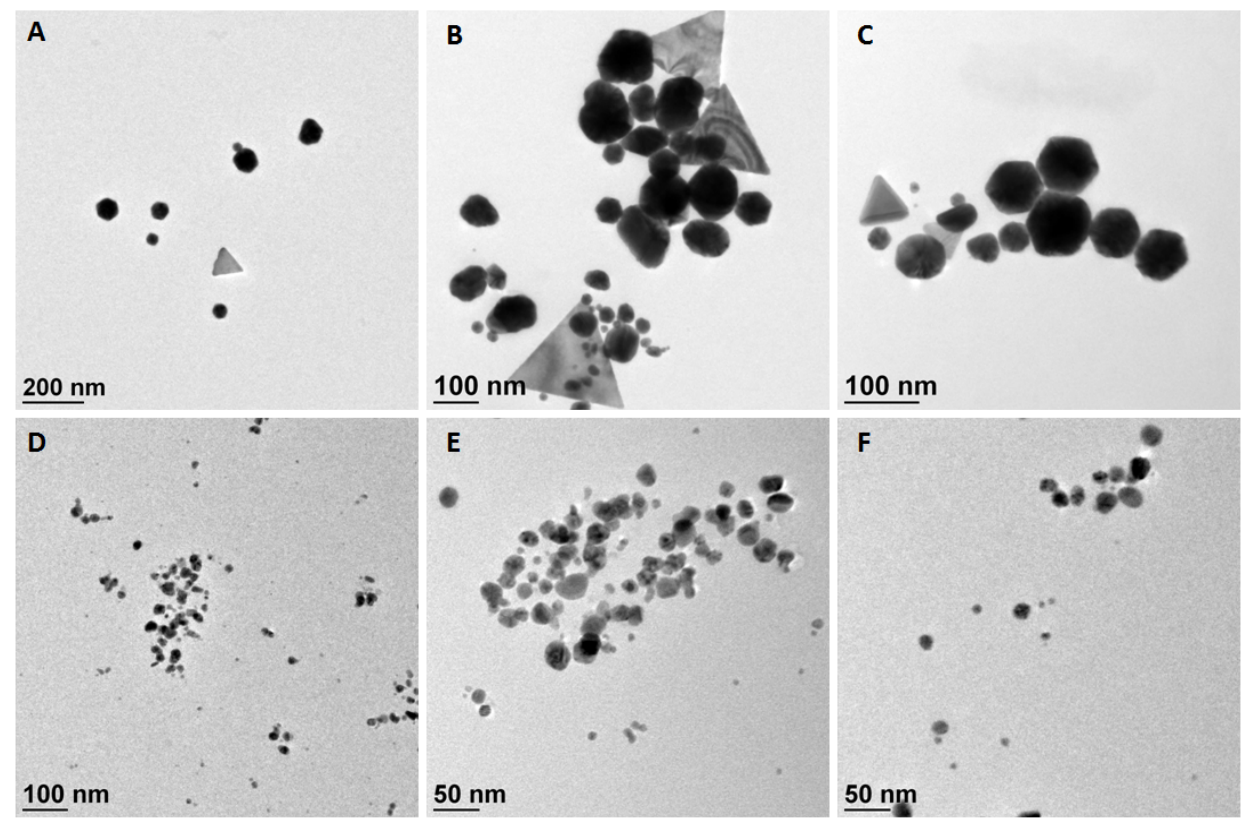

Figure 4: High-resolution transmission electron micrographs of nanoparticles synthesized by POLE. (A) AuNPs bioreduced by POLE, inset bar representing 200 nm; (B) Magnified image showing nanotriangles, nanohexagons along with irregular AuNPs, inset bar representing $100 \mathrm{~nm}$; (C) Distinct blunt ended triangular and hexagonal AuNPs synthesized by POLE, inset bar representing $100 \mathrm{~nm}$; (D) AgNPs synthesized by POLE, inset bar representing $100 \mathrm{~nm}$; (E) Spherical and irregular AgNPs of variable size synthesized by POLE, inset bar representing $50 \mathrm{~nm}$; (F) Magnified image of AgNPs synthesized by POLE, inset bar representing 50 nm.

bioreduced nanoparticles were found in between 10 to $30 \mathrm{~nm}$. Larger nanoparticles were predominantly of irregular shape. Appearance of both smaller and larger nanoparticles in the same frame indicates the assembly and maturation of bioreduced nanomaterials. EDS spectra of the nanoparticles synthesized by POLE confirmed the presence of elemental gold and silver in AuNPs and AgNPs, respectively (Figure 5). The observed peak of $\mathrm{Cu}$ was attributed by the carbon coated copper grids used during analysis. Particle size analysis employing DLS showed that the bioreduced AuNPs were distributed from $10 \mathrm{~nm}$ to $120 \mathrm{~nm}$ in majority (Figure 6A). Similarly, the population of AgNPs synthesized by POLE was found to increase in size from $30 \mathrm{~nm}$ to $120 \mathrm{~nm}$ which decreased thereafter (Figure 6B).

\section{XRD analysis}

The phase formation of the synthesized nanoparticles was studied through X-ray diffraction (XRD). Figure 7A and 7B represent the XRD pattern of AuNPs and AgNPs, respectively. Standard data released by Joint Committee for Powder Diffraction Satndard (JCPDS) were referred to analyze the data obtained. The peaks for AuNPs and AgNPs matched with JCPSD data card no.04-0784 and 04-0783, respectively, confirming the phase formation of the nanoparticles. Lattice planes (111), (200), (220) and (311) at their respective $2 \theta$ values for AuNPs and AgNPs were also observed in the XRD pattern. The lattice constant of the AuNPs and AgNPs was found to be $4.078 \mathrm{~A}^{0}$ and 4.086 $\mathrm{A}^{0}$ respectively. The extra peaks seen in the XRD of AgNPs may be attributed due to the crystalline nature of the unreacted precursor.

FTIR analysis helped in understanding the role of POLE in reduction and stabilization. Hence FTIR spectra of POLE were recorded before bioreduction and after bioreduction as represented in Figure 8. The peak at $1620 \mathrm{~cm}^{-1}$ represent $\mathrm{C}=\mathrm{N}$ stretch, $1375 \mathrm{~cm}^{-1}$ represent $\mathrm{C}-\mathrm{N}$ stretch, $1220 \mathrm{~cm}^{-1}$ represent C-O stretch and $1070 \mathrm{~cm}^{-1}$ represent ether linkages found phytochemicals present in POLE. Presence of phenols/ alcohol can be seen through the broad and strong peak at $\sim 3380 \mathrm{~cm}^{-1}$ which was common before and after synthesis of AuNPs and AgNPs. Another peak at $1620 \mathrm{~cm}^{-1}$ also remained intact before and after reduction of metals ions, while peaks corresponding to $\mathrm{C}=\mathrm{N}$ and $\mathrm{OH}$ groups might be responsible for stabilizing the nanoparticles. The FTIR analysis not only confirms the predominance of various groups of phytochemicals like polyphenols, flavonoids, alkaloids, reducing sugars which are rationalized by the observed functional groups in the spectra. 

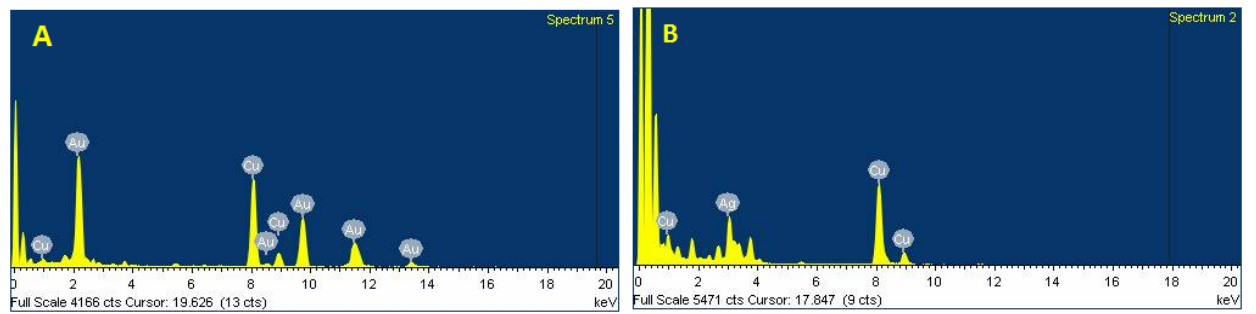

Figure 5: Representative spot EDS profile of (A) AuNPs and (B) AgNPs bioreduced by POLE.
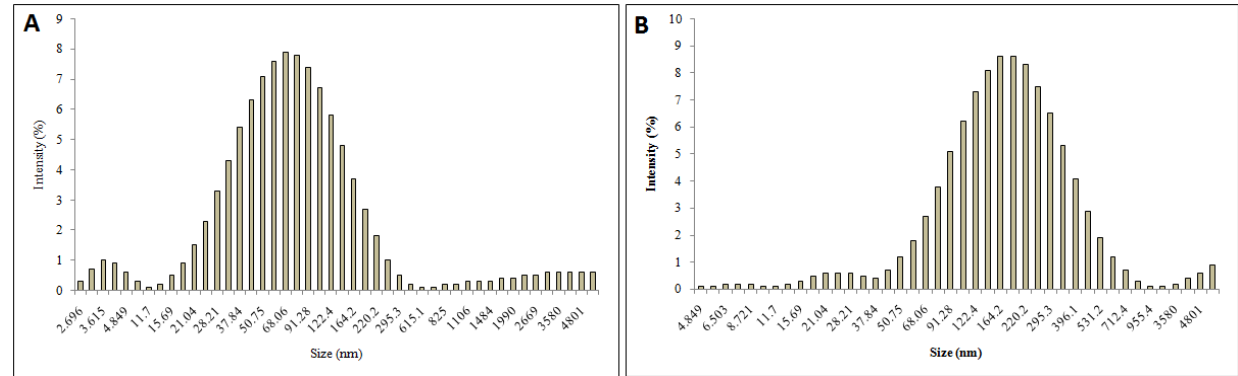

Figure 6: Histogram of size distribution of nanoparticles synthesized by POLE. (A) AuNPs and (B) AgNPs.
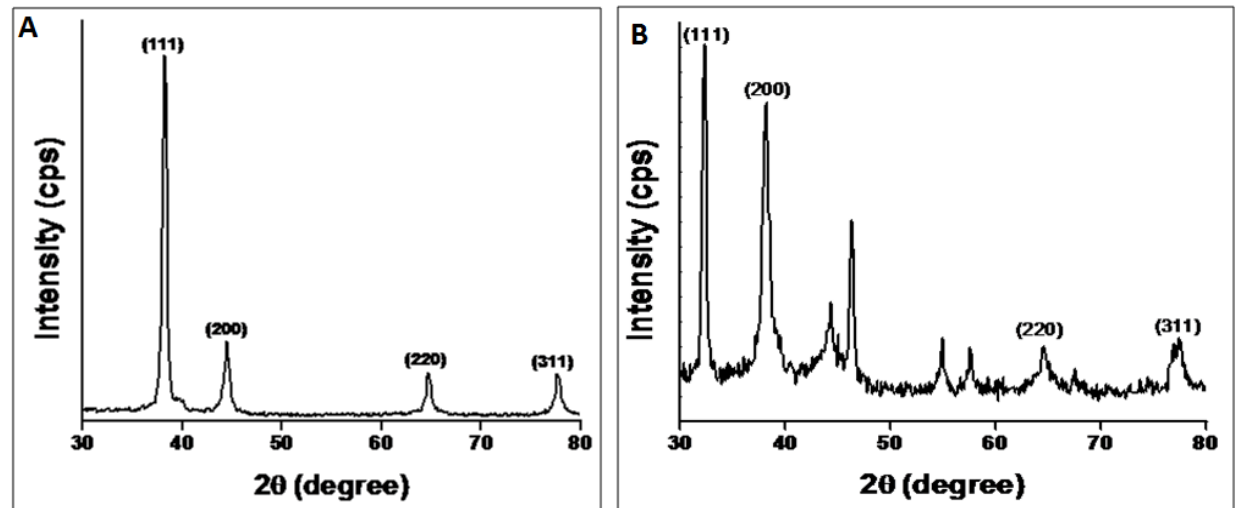

Figure 7: Representative X-ray diffraction profile of thin film AuNPs (A) and AgNPs (B) synthesized by POLE.

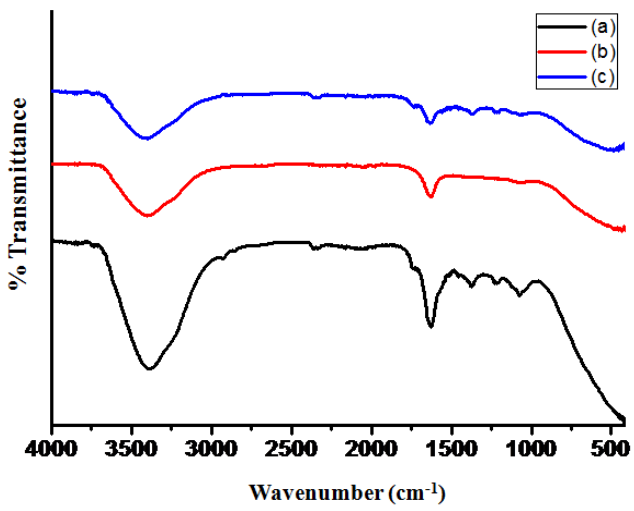

Figure 8: Fourier transform infrared absorption spectra of LCPE before bioreduction (a) and after complete bioreduction of AuNPs (b) and AgNPs (c).

\section{Phytochemical contents}

Phtochemical analysis by biochemical assays showed the predominance of very high concentration of reducing sugars followed by citric acid. POLE also showed the presence of ascorbic acid and phenolic content to significant levels (Table 1). Presence of starch was also detected in POLE. 
Citation: Shende S, Joshi KA, Kulkarni AS, Charolkar C, Shinde VS, et al. (2018) Platanus orientalis Leaf Mediated Rapid Synthesis of Catalytic Gold and Silver Nanoparticles. J Nanomed Nanotechnol 9: 494. doi: 10.4172/2157-7439.1000494

Page 5 of 7

\begin{tabular}{|c|c|c|c|c|c|}
\hline Phytochemicals & Total phenolic content & Citric acid & Ascorbic acid & Total reducing sugar & Total starch \\
\hline Concentration $(\boldsymbol{\mu g} / \mathrm{ml})$ & 64.33 & 456.67 & 184 & 1216.67 & 77.66 \\
\hline
\end{tabular}

Table 1: Phytochemical composition of POLE.

\begin{tabular}{|c|c|c|c|c|}
\hline Sr. No. & Compound Names & Retention Time (min) & Formula & Molecular weight \\
\hline & Octadecanoic acid, (2-phenyl-1,3-dioxolan-4-yl)methyl ester, cis- & 8.09 & $\mathrm{C}_{28} \mathrm{H}_{46} \mathrm{O}_{4}$ & 446 \\
\hline & 2-Myristynoyl pantetheine & 9.19 & $\mathrm{C}_{25} \mathrm{H}_{44} \mathrm{~N}_{2} \mathrm{O}_{5} \mathrm{~S}$ & 484 \\
\hline & Strychane, 1-acetyl-20a-hydroxy-16-methylene & 9.92 & $\mathrm{C}_{21} \mathrm{H}_{26} \mathrm{~N}_{2} \mathrm{O}_{2}$ & 338 \\
\hline & Dodecane, 2,6,10-trimethyl- & 11.02 & $\mathrm{C}_{15} \mathrm{H}_{32}$ & 212 \\
\hline & Octadecane, 3-ethyl-5-(2-ethylbutyl)- & 11.22 & $\mathrm{C}_{26} \mathrm{H}_{54}$ & 366 \\
\hline & Tetradecane, 2,6,10-trimethyl- & 12.6 & $\mathrm{C}_{17} \mathrm{H}_{36}$ & 240 \\
\hline & 2-Myristynoyl pantetheine & 15.1 & $\mathrm{C}_{25} \mathrm{H}_{44} \mathrm{~N}_{2} \mathrm{O}_{5} \mathrm{~S}$ & 484 \\
\hline & cis-13-Eicosenoic acid & 15.85 & $\mathrm{C}_{20} \mathrm{H}_{38} \mathrm{O}_{2}$ & 310 \\
\hline & Dodecane & 16.17 & $\mathrm{C}_{12} \mathrm{H}_{26}$ & 170 \\
\hline & 1-Dodecanol, 3,7,11-trimethyl- & 16.6 & $\mathrm{C}_{15} \mathrm{H}_{32} \mathrm{O}$ & 228 \\
\hline & Geranylisovalerate & 17.77 & $\mathrm{C}_{15} \mathrm{H}_{26} \mathrm{O}_{2}$ & 238 \\
\hline & Ethanol, 2-(octadecyloxy)- & 19.63 & $\mathrm{C}_{20} \mathrm{H}_{42} \mathrm{O}_{2}$ & 314 \\
\hline & Dodecane, 5,8-diethyl- & 21.97 & $\mathrm{C}_{16} \mathrm{H}_{34}$ & 226 \\
\hline & Tetradecane & 22.93 & $\mathrm{C}_{14} \mathrm{H}_{30}$ & 198 \\
\hline & Heptadecane, 2,6,10,15-tetramethyl- & 25.65 & $\mathrm{C}_{21} \mathrm{H}_{44}$ & 296 \\
\hline & Pentadecane, 3-methyl- & 28.15 & $\mathrm{C}_{16} \mathrm{H}_{34}$ & 226 \\
\hline & Hexadecane & 29 & $\mathrm{C}_{16} \mathrm{H}_{34}$ & 226 \\
\hline & Heptacosane & 31.68 & $\mathrm{C}_{27} \mathrm{H}_{56}$ & 380 \\
\hline & Octadecane & 34.46 & $\mathrm{C}_{18} \mathrm{H}_{38}$ & 254 \\
\hline & Ethanol, 2-(9-octadecenyloxy)-, (Z)- & 35.4 & $\mathrm{C}_{20} \mathrm{H}_{40} \mathrm{O}_{2}$ & 312 \\
\hline & Cholestan-3-ol, 2-methylene-, $(3 \beta, 5 \alpha)-$ & 36.48 & $\mathrm{C}_{28} \mathrm{H}_{48} \mathrm{O}$ & 400 \\
\hline & $\mathrm{n}$-Hexadecanoic acid & 38.51 & $\mathrm{C}_{16} \mathrm{H}_{32} \mathrm{O}_{2}$ & 256 \\
\hline & Estra-1,3,5(10)-trien-17ß-ol & 39.4 & $\mathrm{C}_{18} \mathrm{H}_{24} \mathrm{O}$ & 256 \\
\hline & Phytol & 41.88 & $\mathrm{C}_{20} \mathrm{H}_{40} \mathrm{O}$ & 296 \\
\hline & 9,12,15-Octadecatrienoic acid, (Z,Z,Z)- & 42.57 & $\mathrm{C}_{18} \mathrm{H}_{30} \mathrm{O}_{2}$ & 278 \\
\hline & Ursolic aldehyde & 50.16 & $\mathrm{C}_{30} \mathrm{H}_{48} \mathrm{O}_{2}$ & 440 \\
\hline & $\beta$-Sitosterol & 51.54 & $\mathrm{C}_{29} \mathrm{H}_{50} \mathrm{O}$ & 414 \\
\hline & Betulin & 51.55 & $\mathrm{C}_{30} \mathrm{H}_{50} \mathrm{O}_{2}$ & 442 \\
\hline & $\begin{array}{l}\text { Cyclopenta[d]anthracene-8,11-dione, 1,2,3,3a,4,5,6,6a,7,8,11,12- } \\
\text { dodecahydro-3-(1-methylethyl)-12-hydroxy- }\end{array}$ & 52.23 & & \\
\hline & Olean-12-ene-3,15,16,21,22,28-hexol, $(3 \beta, 15 \alpha, 16 \alpha, 21 \beta, 22 \alpha)$ - & 53.72 & $\mathrm{C}_{30} \mathrm{H}_{50} \mathrm{O}_{6}$ & 506 \\
\hline & Retinoyl- $\beta$-glucuronide 6',3'-lactone & 54.05 & $\mathrm{C}_{26} \mathrm{H}_{34} \mathrm{O}_{7}$ & 458 \\
\hline
\end{tabular}

Table 2: Main compounds detected by GCMS analysis in POLE.
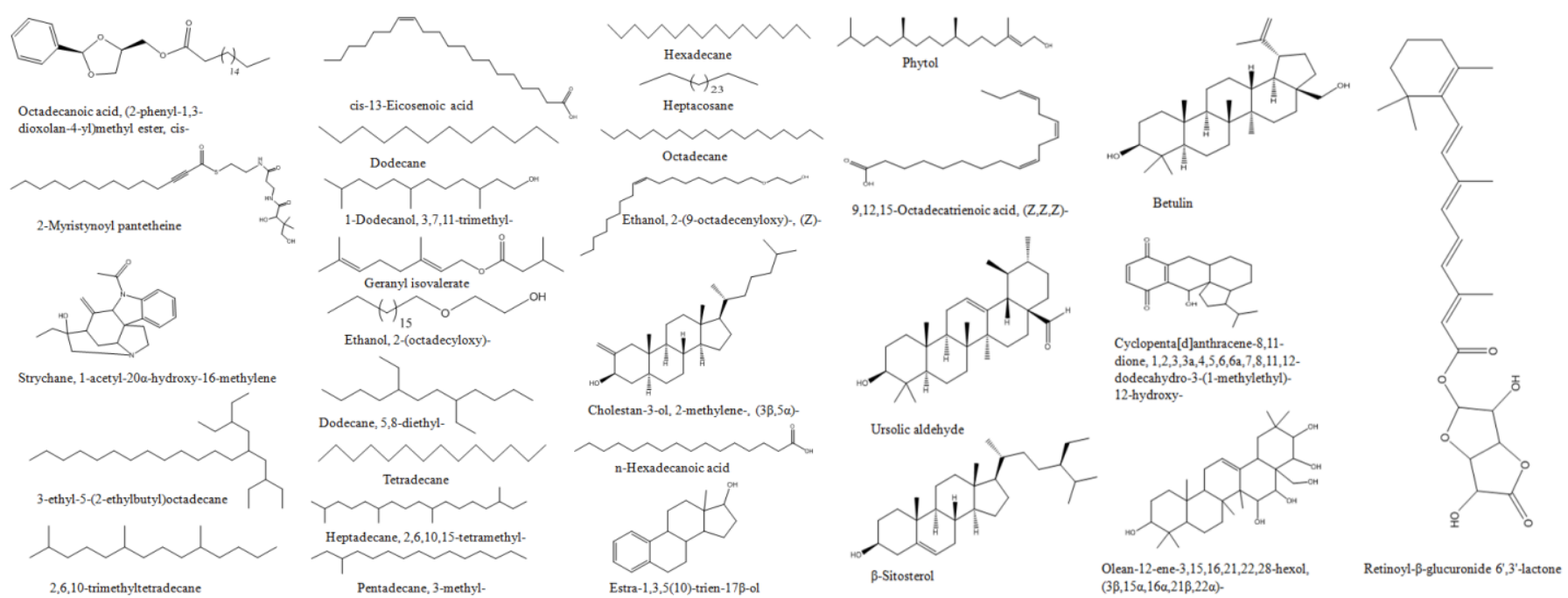

Figure 9: Representative structures of the major phytochemicals identified in POLE by GCMS analysis. 

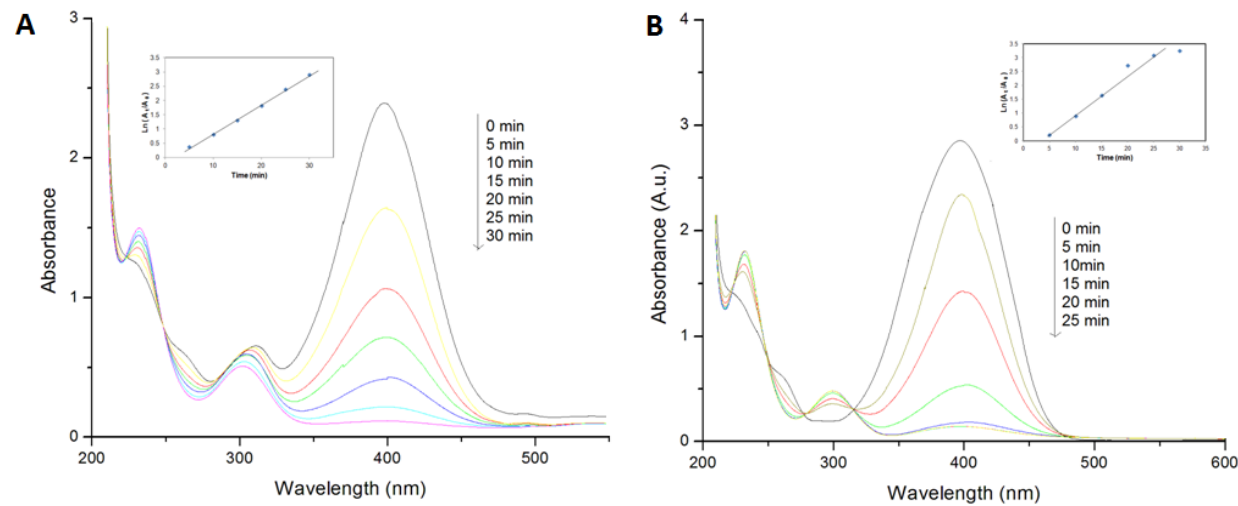

Figure 10: UV-vis absorption spectra during the reduction of 4-nitrophenol as a function of chemocatalytic activity of (A) AuNPs and (B) AgNPs synthesized by POLE. Inset figures represent plot of $\ln \left(A_{1} / A_{0}\right)$ versus time for the reduction of 4-NP.

\section{GCMS analysis}

GCMS analysis of POLE showed the presence of Dodecane, 2,6,10-trimethyl-, Dodecane, Tetradecane, Hexadecane, n-Hexadecanoic acid, 9,12,15-Octadecatrienoic acid, (Z,Z,Z)- as most predominant compounds which might play an important role towards synthesis and stabilization of AuNPs and AgNPs (Table 2). A diverse group of phytochemicals were evident from the GCMS analysis (Figure 9). Various compounds with aromatic ring, conjugated double bonds containing long side chains and hydroxyl groups could be seen among the predominant compounds. The compounds observed belong to diverse groups of alkanes, alkenes, alcohols and esters.

\section{Catalytic activity}

Catalytic efficiencies of AuNPs and AgNPs were evaluated using 4-nitrophenol (4-NP) to 4-aminophenol (4-AP) model reduction using $\mathrm{NaBH}_{4}$. Upon addition of sodium borohydride, pale color of 4-NP was gradually converted to intense yellow indicating formation of 4-nitrophenolate ion. After the addition of AuNPs, yellow color of this solution faded gradually indicating conversion of nitro to amine group. UV-vis spectroscopy was employed to monitor the progress of the reaction, as shown in Figure 10. The characteristic peak of 4-NP at $400 \mathrm{~nm}$ decreased, while a new peak appeared at $290 \mathrm{~nm}$ due to formation of 4-AP which completed within $30 \mathrm{~min}$.

Similar observation was noted for AgNPs as well. Linear relation between $\ln \left(A_{t} / A_{0}\right)$ verses time $\mathrm{t}$, obtained in case of both AuNPs and AgNPs are represented in the inset of Figure 10A and 10B. The reactions followed pseudo-first order rate kinetics and the apparent rate constant $(k)$ determined for AuNPs and AgNPs were $1.908 \times 10^{-4}$ $\min ^{-1}$ and $3.071 \times 10^{-4} \mathrm{~min}^{-1}$, respectively.

\section{Discussion}

Medicinal plants are considered as store houses of diverse groups of phytochemicals which can be efficiently exploited for therapeutic purposes, chemical reactions and more recently in nanobiotechnology [25-31]. POLE exhibited excellent potential to reduce $\mathrm{Au}^{3+}$ and $\mathrm{Ag}^{+}$ ions to $\mathrm{Au}$ and $\mathrm{Ag}$ within $5 \mathrm{~h}$ which was found to be effective compared to earlier reports with Sesuvium portulacastrum L that take 24 hours for complete synthesis of AgNPs [32]. Development of intense brown and red colour confirmed the synthesis of AgNPs and AuNPs which was in agreement with the earlier reports with Litchi chinensis, Gloriosa superba and Dioscorea oppositifolia $[9,17,18]$. Optimization studies revealed that higher temperature facilitated the rate of synthesis while concentration of salt could enhance upto a certain limit beyond which the increase in salt concentration fails to show any visible increase in rate of synthesis [33]. The bioreduced nanoparticles exhibited anisotropic morphology with exotic shapes like nanotriangles, spheres and blunt ended hexagons. Similar anisotropy was reported during synthesis using Dioscorea bulbifera and Plumbago zeylanica $[10,11,19]$. $P$. orientalis was found to possess various phytochemicals like phenolic, citric acid, ascorbic acid and reducing sugars which might help in reduction while starch may play a key role in stabilization. Similarly, GCMS analysis indicated a plethora of active principles in $P$. orientalis which might help synergistically in the process of bioreduction and stabilization [16-18]. Both AuNPs and AgNPs showed efficient catalytic potential for reduction of 4-nitrophenol (4-NP) to 4-aminophenol (4AP) using $\mathrm{NaBH}_{4}$. Biologically synthesized nanoparticles are found to be more effective and biocompatible. However, there is a probability that capping with biomaterials may render the nanoparticles ineffective for chemical applications. Interestingly, POLE synthesized AuNPs and AgNPs were catalytically active which can be well supported by earlier reports [34].

\section{Conclusion}

In the present study, $P$. orientalis leaf extract was used to synthesize AgNPs and AuNPs which was found to be efficient, economically viable and environmentally benign. This one pot synthesis with optimized parameters can prove to be advantageous for large scale synthesis of size and shape controlled well dispersed nanoparticles. Both, bioreduced AgNPs and AuNPs displayed efficient catalytic potential by reduction of 4-nitrophenol to 4-aminophenol following a pseudo-first order rate kinetics. Thus, AgNPs and AuNPs synthesized by POLE are of immense economical and industrial significance.

\section{References}

1. Kitsou I, Panagopoulos P, Maggos T, Arkas M, Tsetsekou A (2018) Development of $\mathrm{SiO}_{2} @ \mathrm{TiO}_{2}$ core-shell nanospheres for catalytic applications. Applied Surface Science 441: 223-231.

2. Ghosh S, More P, Derle A, Kitture R, Kale T, et al. (2015) Diosgenin functionalized iron oxide nanoparticles as novel nanomaterial against breast cancer. J Nanosci Nanotechnol 15: 9464-9472.

3. Asok A, Kulkarni AR, Ghosh S, More P, Chopade BA, Gandhi MN (2015) Surface defect rich $\mathrm{ZnO}$ quantum dots as antioxidant inhibiting $\alpha$-amylase and $\alpha$-glucosidase: A potential anti-diabetic nanomedicine. J Mater Chem B 3: 4597-4606.

4. Mallick A, More P, Ghosh S, Chippalkatti R, Chopade BA, et al. (2015) Dua drug conjugated nanoparticle for simultaneous targeting of mitochondria and nucleus in cancer cells. ACS Appl Mater Interfaces 7: 7584-7598. 
Citation: Shende S, Joshi KA, Kulkarni AS, Charolkar C, Shinde VS, et al. (2018) Platanus orientalis Leaf Mediated Rapid Synthesis of Catalytic Gold and Silver Nanoparticles. J Nanomed Nanotechnol 9: 494. doi: 10.4172/2157-7439.1000494

5. Sant DG, Gujarathi TR, Harne SR, Ghosh S, Kitture R, et al. (2013) Adiantum philippense L. frond assisted rapid green synthesis of gold and silver nanoparticles. Journal of Nanoparticles 1-9.

6. Kitture R, Ghosh S, Kulkarni P, Liu XL, Maity D, et al. (2012) $\mathrm{Fe}_{3} \mathrm{O}_{4}$-citrate curcumin: Promising conjugates for superoxide scavenging, tumor suppression and cancer hyperthermia. J Appl Phys 111: 064702.

7. Ghosh S, Jagtap S, More P, Shete UJ, Maheshwari NO, et al. (2015) Dioscorea bulbifera mediated synthesis of novel AucoreAgshell nanoparticles with potent antibiofilm and antileishmanial activity. J Nanomater.

8. Rokade SS, Joshi KA, Mahajan K, Tomar G, Dubal DS, et al. (2017) Global J Nanomedicine 2: 555600.

9. Shende S, Joshi KA, Kulkarni AS, Shinde VS, Parihar VS, et al. (2017) Litch chinensis peel: A novel source for synthesis of gold and silver nanocatalysts. Global J Nanomedicine 3: 555603.

10. Ghosh S, Patil S, Ahire M, Kitture R, Kale S, et al. (2012) Synthesis of silver nanoparticles using Dioscorea bulbifera tuber extract and evaluation of its synergistic potential in combination with antimicrobial agents. Int $J$ Nanomedicine 7: 483-496.

11. Ghosh S, Patil S, Ahire M, Kitture R, Jabgunde A, et al. (2011) Synthesis of gold nanoanisotrops using Dioscorea bulbifera tuber extract. J Nanomater.

12. Ghosh S, More P, Nitnavare R, Jagtap S, Chippalkatti R, et al. (2015) Antidiabetic and antioxidant properties of copper nanoparticles synthesized by medicinal plant Dioscorea bulbifera. J Nanomed Nanotechnol S6: 007.

13. Ghosh S, Nitnavare R, Dewle A, Tomar GB, Chippalkatti R, et al. (2015) Nove platinum-palladium bimetallic nanoparticles synthesized by Dioscorea bulbifera : anticancer and antioxidant activities. Int J Nanomed 10: 7477-7490.

14. Ghosh S, Patil S, Ahire M, Kitture R, Gurav DD, et al. (2012) Gnidia glauca flower extract mediated synthesis of gold nanoparticles and evaluation of its chemocatalytic potential. J Nanobiotechnol 10: 17.

15. Ghosh S, Patil S, Chopade NB, Luikham S, Kitture R, et al. (2016) Gnidia glauca leaf and stem extract mediated synthesis of gold nanocatalysts with free radical scavenging potential. J Nanomed Nanotechnol 7: 2 .

16. Ghosh S, Gurav SP, Harke AN, Chacko MJ, Joshi KA, et al. (2016) Dioscorea oppositifolia mediated synthesis of gold and silver nanoparticles with catalytic activity. J Nanomed Nanotechnol 7: 5 .

17. Ghosh S, Chacko MJ, Harke AN, Gurav SP, Joshi KA, et al. (2016) Barleria prionitis leaf mediated synthesis of silver and gold nanocatalysts. J Nanomed Nanotechnol 7: 4.

18. Ghosh S, Harke AN, Chacko MJ, Gurav SP, Joshi KA, et al. (2016) Gloriosa superba mediated synthesis of silver and gold nanoparticles for anticancer applications. J Nanomed Nanotechnol 7: 4

19. Salunke GR, Ghosh S, Kumar RJS, Khade S, Vashisth P, et al. (2014) Rapid efficient synthesis and characterization od AgNPs, AuNPs and AgAuNPs from a medicinal plant, Plumbago zeylanica and their application in biofilm control. Int J Nanomedicine 9: 2635-2653.
20. Irtiza S, Bhat GA, Ahmad M, Ganaie HA, Ganai BA, et al. (2016) Antioxidant and anti-inflammatory activities of Platanus orientalis: An oriental plant endemic to Kashmir planes. Pharmacologia 7: 217-222.

21. Hajhashemi V, Ghannadi A, Mousavi S (2011) Antinociceptive study of extracts of Platanus orientalis leaves in mice. Res Pharm Sci 6: 123-128.

22. Tantry MA, Akbar S, Dar JA, Irtiza S, Galal A, et al. (2012) Acylated flavono glycoside from Platanus orientalis. Fitoterapia 83: 281-285.

23. Haider S, Nazreen S, Alam MM, Hamid H, Alam MS (2012) Anti-inflammatory and anti-nociceptive activities of Platanus orientalis Linn. and its ulcerogenic risk evaluation. J Ethnopharmacol 143: 236-240.

24. Thai QD, Tchoumtchoua J, Makropoulou M, Boulaka A, Meligova AK, et al. (2016) Phytochemical study and biological evaluation of chemical constituents of Platanus orientalis and Platanus acerifolia buds. Phytochemistry 130: $170 \mathrm{e} 181$.

25. Kitture R, Ghosh S, More PA, Date K, Gaware S, et al. (2015) Curcuminloaded, self-assembled Aloe vera template for superior antioxidant activity and trans-membrane drug release. J Nanosci Nanotechnol 15: 4039-4045.

26. Kitture R, Chordiya K, Gaware S, Ghosh S, More P A, et al. (2015) ZnO nanoparticles-red sandalwood conjugate: A promising anti-diabetic agent. $J$ Nanosci Nanotechnol 15: 4046-4051.

27. Ghosh S, More P, Derle A, Patil AB, Markad P, et al. (2014) Diosgenin from Dioscorea bulbifera: novel hit for treatment of Type II Diabetes Mellitus with inhibitory activity against $\alpha$-amylase and $\alpha$-glucosidase. PLoS One 9: e106039.

28. Ghosh S, Parihar VS, Dhavale DD, Chopade BA (2015) Commentary on therapeutic potential of Gnidia glauca: A novel medicinal plant. Med Chem 5 351-353.

29. Ghosh S, Parihar VS, More P, Dhavale DD, Chopade BA (2015) Phytochemistry and therapeutic potential of medicinal plant : Dioscorea bulbifera. Med Chem 5: 154-159.

30. Ghosh S, Derle A, Ahire M, More P, Jagtap S, et al. (2013) Phytochemical analysis and free radical scavenging activity of medicinal plants Gnidia glauca and Dioscorea bulbifera. Plos One 8: e82529.

31. Ghosh S, Ahire M, Patil S, Jabgunde A, Bhat Dusane M, et al. (2012) Antidiabetic activity of Gnidia glauca and Dioscorea bulbifera: potent amylase and glucosidase inhibitors. Evid Based Complement Alternat Med.

32. Nabikhan A, Kandasamy K, Raj A, Alikunhi NM (2010) Synthesis of antimicrobia silver nanoparticles by callus and leaf extracts from saltmarsh plant, Sesuvium portulacastrum L. Colloids Surf B Biointerfaces 79: 488-493.

33. Song JY, Kim BS (2009) Rapid biological synthesis of silver nanoparticles using plant leaf extracts. Bioprocess Biosyst Eng 32:79-84.

34. Gangula A, Podila R, Ramakrishna M, Karnam L, Janardhana C, et al. (2011) Catalytic reduction of 4-nitrophenol using biogenic gold and silver nanoparticles derived from Breynia rhamnoides. ACS Langmuir 27: 15268-15274. 